\title{
Laparoscopic Living Kidney Donation
}

\author{
Leonienke F.C. Dols and Jan N.M. IJzermans \\ Erasmus MC Rotterdam \\ The Netherlands
}

\section{Introduction}

Kidney transplantation is the therapy of choice for patients with end-stage renal disease and gives the best chance on long-term survival with a good quality of life. Allografts can be procured from living and deceased donors. Since the successful kidney transplantations in the early 1950s by Rene Kuss and Joseph Murray great progress has been made in this field of medicine.[1] With the introduction of adequate immunosuppressive therapy in the 1960s and new organ preservation techniques the outcome of the transplantation procedures using deceased donor kidneys improved significantly and the use of living donors became an exception as the risk of living kidney donor were thought to be unacceptable. Furthermore, in those years there was an adequate number of deceased donors to accommodate the number of patients on the waiting lists.

In the late 80 s a growing discrepancy was noted between organ demand and supply due to an increasing number of patients with end-stage renal disease (ESRD) included for transplantation and a stagnating number of organ donors. The average waiting time for a kidney transplant from a deceased donor increased significantly and up to twenty percent of patients on dialysis had to be removed from the waiting list annually because of a worsening condition or even mortality. This encouraged a new interest in live donor kidney transplantation and in the last decade the number of transplants from live donors significantly increased in the Western World. In addition, the use of live kidney donor transplantation created new opportunities, including crossover programs and pre-emptive and ABO-incompatible kidney transplantations. All these developments contributed to the success of live kidney donation at present and popularity is still increasing in many countries. Today the expansion of live kidney donation may be considered as the most realistic option to solve the problem of kidney donor shortage. The ongoing stream of technical innovations and social, ethical and psychological research focused on live kidney donation legitimize the increasing use of living donors.

Renal transplantation from living donors confers several advantages as compared to dialysis and transplantation from deceased donors, including improved longer-term patient survival, better quality of life, immediate functioning of the transplant, better transplant survival, and the possibility of transplanting pre-emptively. To date the health of live kidney donors at long-term follow-up is good, and the procedure is considered to be safe. Due to good outcome of living kidney donors, the boundaries for acceptance of kidney donors are shifting towards a wider acceptance. Donors with higher body mass index (BMI), moderate hypertension, older age or kidneys with multiple arteries are nowadays accepted.[2-8] 
Currently, attention to donor wellbeing has become a priority, and therefore the surgical technique must be optimized continually. Surgical practice has evolved from the open lumbotomy, through mini-incision muscle-splitting open (MIDN), to minimally invasive laparoscopic techniques. Over the last years many changes have been introduced in the field of living kidney donor nephrectomy. Laparoscopic donor nephrectomy is now the gold standard. There are different minimally invasive techniques, including standard laparoscopic, handassisted laparoscopic, hand-assisted retroperitoneoscopic, pure retroperitoneoscopic, and robotic-assisted live donor nephrectomy. Different centres have different visions and experience on which technique to use. In the literature, there is level I evidence that minimally invasive techniques are preferred above open donor nephrectomy.[9] Optimizing the donation procedure is mainly focused on donor safety and includes proper definition of criteria for inclusion of donors, anaesthetic and surgical aspects and post-operative care. Long-term follow-up may be offered as surveillance program to detect potential threats for the donors health such as hypertension, protein loss or overweight.

In this chapter we'll address the surgical procedure of live kidney donation and discuss aspects that may influence successful outcome.

\section{Pre-operative}

\subsection{Standard evaluation of the donor}

Selection of live kidney donors is mixed by ethical and medical issues. It is only justified if the harm to the donor is limited and the potential benefit to the recipient is major. The risk for the short-term and long-term adverse health consequences to the donor is therefore essential. The Amsterdam Forum has established guidelines for the (relative) contraindications to live kidney donation: donors must have sufficient renal function (GFR more than $80 \mathrm{ml} / \mathrm{min}$ ), no hypertension (less than 140/90 $\mathrm{mm} \mathrm{Hg}$ ), no obesity (BMI less than 35 $\mathrm{kg} / \mathrm{m}^{2}$ ), negative urine analysis for protein (less than $300 \mathrm{mg} / 24$ hours) and erythrocytes, no diabetes, stone disease, malignancy or urinary tract infections, a minor or no cardiovascular or pulmonary risk and smoking cessation and alcohol abstinence is obligatory. To ensure donor safety, every donor should be offered a number of standard tests, including blood and urine screening, chest x-ray, electrocardiogram (ECG), radiographic assessment of the kidneys and vessels via renal ultrasound, computed tomography (CT) with intravenous contrast or magnetic resonance imaging (MRI) with intravenous contrast, psychological evaluation, and age- and family history-appropriate additional cardiac testing.[10]

A multidisciplinary approach including nephrologists, transplant surgeons, urologists, and psychologists is required to optimize the quality of a live kidney donation program in each hospital. Disciplines have to cooperate in the screening of donors and informing relatives without exerting pressure on potential donors. Each step in the multidisciplinary approach should be optimized. Imaging of the donor kidney should be performed without any complications and the surgical procedure should be organised with optimal peri-operative care to minimize pain and discomfort to the donor. Advances in surgical technique have improved the comfort of the donor considerably and the risks of morbidity and mortality have been minimized.

\subsection{Choices in the selection of living kidney donors 2.2.1 Side selection}

Meticulous preoperative preparation of donor operations has become increasingly important as vascular anatomy may significantly influence safety and surgical outcome. 
Traditionally, the donor's renal anatomy was assessed by angiography with good results but with significant consequences for the donor including radiation and a short stay in the hospital. Magnetic Resonance Imaging (MRI) and Computed Tomography (CT) have both been reported feasible alternatives.[11, 12]Angiography was gradually replaced by MRI as this technique does not cause radiation and, in addition, provides information on venous anatomy. Recently, new CT-protocols allow the use of minimal radiation while offering optimal imaging of the renal anatomy and they may be used safely in the work-up of selected donors.

If both kidneys have a normal or comparable anatomy regarding the number of renal vessels there is the issue of choosing the right or left kidney, especially in those cases where a laparoscopic approach is considered. Right-sided donor nephrectomy has been associated with a shorter renal vein and renal vein thrombosis in the recipient. Reluctance towards the right side arose when Mandal et al. described a worse outcome for right kidneys with significantly more renal vein thrombosis. [13] One RCT, one prospective and some retrospective studies concluded that right sided-donor nephrectomy is also justified, and in some studies indicate the superiority of the right side. [14-21] In theory a shorter renal vein may lead to a more difficult anastomosis, but no studies so far confirmed this concept.

Another issue is the use of kidneys with multiple arteries. The rationale was to avoid vascular and ureteral complications by using only kidneys with single arteries. But as there were doubts about the use of the right kidney, many centres favoured left donor nephrectomy even in the presence of multiple arteries. Live donor kidneys with multiple arteries are associated with increased surgical complexity for removal and increased rate of recipient ureteral complications. Multiple arteries may increase operation time and risk for the donor. Accessory lower pole arteries are associated with a higher rate of recipient ureteral complications indicating the importance of arterial imaging.

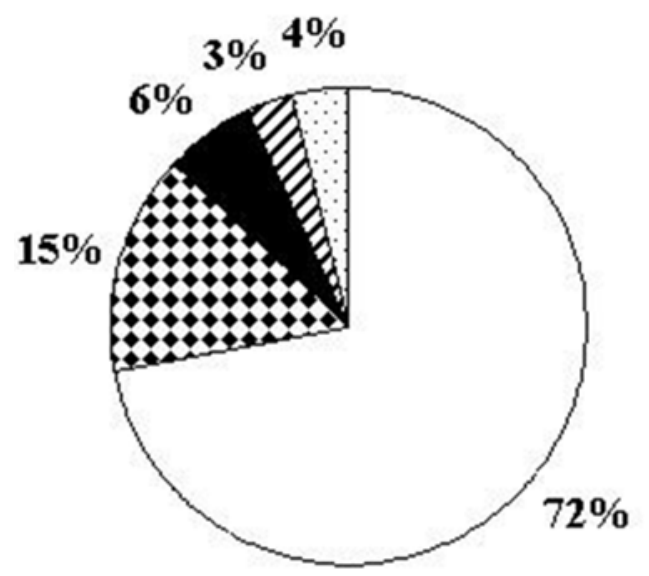

\begin{tabular}{|l|}
\hline 1 artery 1 vein \\
$\square 2$ arteries 1 vein \\
$\square 1$ artery 2 veins \\
$\square 2$ arteries 2 veins \\
$\square$ miscellaneous \\
\hline
\end{tabular}

Kok et al, Transplantation. 2008 Jun 27;85(12):1760-5.

Fig. 1. Variation in arterial and venous anatomy

At present there are studies, one prospective and a small number of retrospective studies comparing single and multiple arteries. All studies included a relative small number of donors with multiple arteries and indicate the safety and feasibility of donor nephrectomy in case of multiple arteries. Two studies suggest that multiple renal arteries are associated 
with more ureteral complications in the recipient, especially when accessory arteries to the lower renal pole are involved. [12, 22-24]

\begin{tabular}{lccc}
\hline & $\begin{array}{c}\text { Single artery } \\
(\mathrm{n}=138)\end{array}$ & $\begin{array}{c}\text { Multiple arteries } \\
(\mathrm{n}=47)\end{array}$ & P-value \\
\hline Warm ischemia time (minutes) & $6.0(2.8)$ & $7.3(3.1)$ & 0.009 \\
Time until kidney extraction (minutes) & $182(48)$ & $204(55)$ & 0.023 \\
Skin-to-skin time (minutes) & $225(51)$ & $247(57)$ & 0.023 \\
Blood loss (ml) & $220(456)$ & $225(204)$ & 0.029 \\
Intra-operative complications & $22(16 \%)$ & $7(15 \%)$ & 0.864 \\
Postoperative complications & $11(8 \%)$ & $6(13 \%)$ & 0.326 \\
Ureteral complications (recipient) & $30(14 \%)$ & $14(21 \%)$ & 0.127 \\
Ureteral complications leading to re- & $11(5 \%)$ & $7(11 \%)$ & 0.096 \\
operation & & & \\
\hline
\end{tabular}

Kok et al, Transplantation. 2008 Jun 27;85(12):1760-5.

Table 1. Outcomes of procurement of kidneys with single versus multiple arteries by laparoscopic donor nephrectomy. Categorical data are displayed as No. (\%) and continuous variables as mean $(\mathrm{SD})$.

\subsubsection{Age}

Due to the increasing shortage of deceased kidney donors one is trying to expand and maximize the live donor pool. In this transition new criteria are being defined and a number of issues studied as relative contra-indications for the operative procedure include age, body weight and co morbidity of the living donor.

Nowadays, older live donors, obese donors and donors with minor co morbidity indeed may be selected as candidates for kidney donation. There is an ongoing shift towards the acceptance of these donors and the outcome demonstrates the feasibility of this approach in order to bridge the gap between demand and supply of kidney transplants.

Controversy remains, as age related changes in the kidney may result in a decline in renal function over the years, and so far the combination of aging and donor nephrectomy has only been investigated by few. We questioned whether the outcome of older live kidney donation wouldn't hamper the glomerular filtration rate (GFR) on long-term after donation. In addition older donors may also have an increased risk of other perioperative and postoperative complications as they often have a higher 'American Society of Anesthesiologist score' (ASA-score), indicating more comorbidity, a higher incidence of hypertension and a higher Body Mass Index (BMI). All these factors may contribute to a higher risk of complications related to a surgical intervention. Our study demonstrated that the decline in eGFR is similar in younger and older donors. As kidney function does not progressively decline during follow up we believe that, live kidney donation by older donors can be considered safe. Furthermore, we found that graft survival was not compromised in case kidneys from older donors were used.[25-31] 


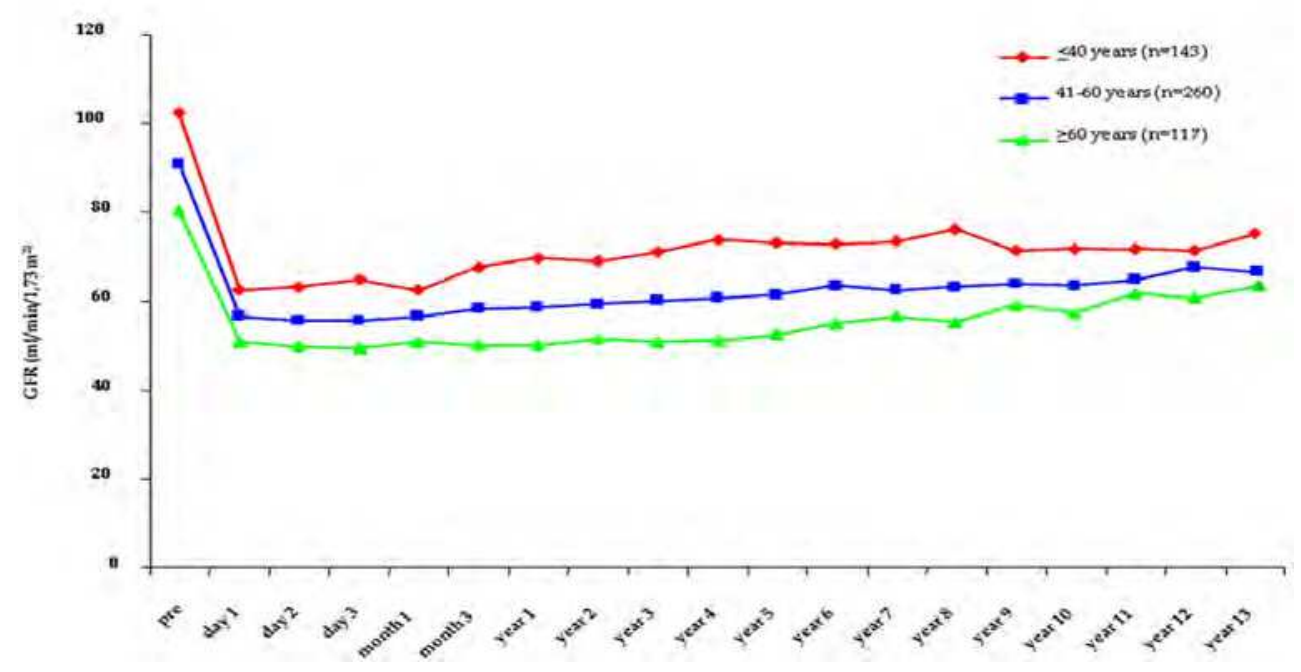

Dols et al. N Engl J Med. 2009 Jan 29;360(5):459-69.

Fig. 2. Glomerular filtrations rate after living donor nephrectomy, divided into age groups.

\begin{tabular}{cccc}
\hline & Hazard ratio & $95 \%-\mathrm{CI}$ & P-value \\
\hline BMI donor & 1.085 & $1.029-1.144$ & 0.003 \\
Mismatch-total & 1.172 & $1.025-1.340$ & 0.020 \\
Age donor & 1.014 & $0.995-1.034$ & 0.169 \\
Age recipient & 0.988 & $0.917-1.005$ & 0.210 \\
Gender donor & 0.895 & $0.563-1.423$ & 0.672 \\
Gender recipient & 0.906 & $0.565-1.452$ & 0.810 \\
\hline
\end{tabular}

Dols et al. Am J Transplant. 2011 Apr;11(4):737-42.

Table 2. Multivariate analysis for the association between clinical variables and graft survival.

\subsubsection{BMI}

To date donors with isolated abnormalities, like obesity, are included in living donation programs. This is a significant challenge for the laparoscopic surgeon. In addition to technical aspects like positioning of the donor, the port-site of the trocars and the instrumentation needed surgeons may face longer and more complex operation procedures with the risk of a higher incidence of anaesthetic and postoperative complications. Studies suggest that laparoscopic donor nephrectomy is safe in selected obese donors. Obese donors 
have higher baseline cardiovascular risk and warrant risk reduction for long-term health. Furthermore obesity acts on renal function, it accounts for an increase in glomerular filtration rate with less elevated or even decreased effective renal plasma flow, and filtration fraction is increased. The filtration fraction is a predictor for renal function loss, independent of blood pressure. Multiple factors are assumed to contribute to these renal hemodynamic alterations such as insulin resistance, the renin-angiotensin system and the tubuloglomerular responses to increased proximal sodium reabsorption, and possibly also inappropriate activity of the sympathetic nervous system and increased leptin levels. Together with donor nephrectomy this might be harmful on long-term follow-up, especially because the incidence of overweight and obesity is increasing. While early operative results are encouraging, we advocate careful study of obese donors, especially for the long-term renal effects.

In general, a body mass index (BMI) below 35 is considered acceptable to undergo donor nephrectomy without increased risks. It remains open for discussion which operative procedure should be preferred in obese donors. LDN has been demonstrated feasible in this category of donors and can lead to equivalent results in obese as in normal weight individuals. In specialized centers in the USA, hand-assisted LDN in overweight and obese donors has become a common practice. Nevertheless, total LDN in overweight and obese donors is definitely more challenging and experience is required to render acceptable results. On the other hand, total LDN may avoid postoperative complications that typically occur in obese individuals such as wound infections and incisional hernias, because there is no hand introduced into the abdominal cavity and the extraction incision is smaller as a hand-port is not required. As opposed to many American centers, many European centers are still reluctant towards LDN in general and LDN in donors with more difficult anatomy in particular. [32-36]

\begin{tabular}{|l|l|l|}
\hline & Level of evidence & Type of evidence \\
\hline Left versus right & II & $\begin{array}{l}\text { - RCT } \\
\text { - Prospective study } \\
\text { - Retrospective studies }\end{array}$ \\
\hline $\begin{array}{l}\text { Multiple arteries vs } \\
\text { single artery }\end{array}$ & III & $\begin{array}{l}\text { - Prospective studies } \\
\text { - Retrospective studies }\end{array}$ \\
\hline $\begin{array}{l}\text { Obese vs non-obese } \\
\text { donors }\end{array}$ & III & -Retrospective study \\
\hline
\end{tabular}

Dols et al, Transpl Int. 2010 Feb;23(2):121-30.

Table 3. Surgical issues surrounding live kidney donation; level and type of evidence.

\section{Intra-operative}

\subsection{Surgical techniques}

Different transplant centers use different techniques. There are a lot of variations in technique, but we tend to describe the most universal way in which these operations are performed. Which surgical technique to use is depending on the preference and experience of the surgeon. In case a surgeon can perform all techniques, minimal invasive techniques are preferred. 


\subsubsection{Open donor nephrectomy: Flank incision versus mini-incision}

With the donor placed in a lateral decubitus position, lumbotomy is performed in the eleventh intercostal space or below the 12th rib. Sometimes a rib resection is mandatory to allow adequate view. The muscles are transected. A mechanical retractor is installed, and the retroperitoneal space opened. The kidney is dissected from its capsula and the arterial and venous structures are identified. After dissection, the ureter is divided and sutured distally. Thereafter, the kidney is extracted, flushed and stored on ice.

Mini-incision muscle-splitting approach (MIDN) is performed with the patient placed in a lateral decubitus position and the operation table maximally flexed. A horizontal $10-15 \mathrm{~cm}$ skin incision is made anterior to the 11th rib towards the umbilicus. Sometimes an anterior vertical incision is made in other centres. The fascia and muscles of the abdominal wall are either split attempting to avoid harming the intercostal nerves or divided. The peritoneum is displaced medially. As the working space is limited long instruments have to be used. Further dissection and preparation of the vascular structures is performed as described above.

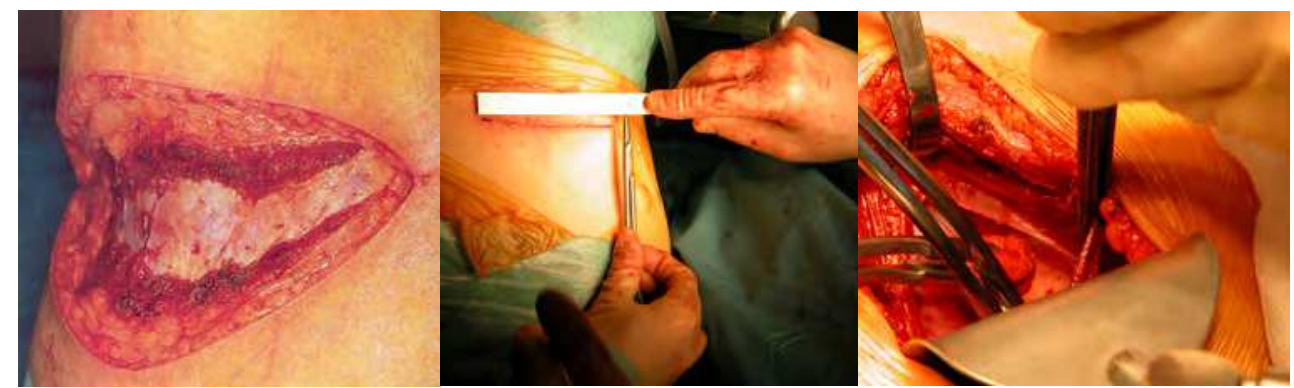

Fig. 3. Flank Incision (left) and mini-incision muscle sparing donor nephrectomy (middle and right).

Conventional open living donor nephrectomy is associated with disincentives including long hospital stay, prolonged postoperative pain, cosmetic problems and long convalescence time. The flank incision technique sometimes required a rib resection, with considerable comorbidity. There is one randomized controlled trial RCT comparing transcostal to subcostal incision (Level II evidence). Srivastava et al. shows that patients in the subcostal group $(n=25)$ had a lesser postoperative analgesic requirement, shorter hospital stay and shorter convalescence time compared with the ribresection transcostal group $(n=24)$. [37] Mini-incision donor nephrectomy (MIDN) results in similar donor safety, as reflected by the absence of major complications, a similar number of minor intra- and postoperative complications and equivalent graft function. Donors benefit from reduced blood loss, shorter hospitalization, and preservation of continuity of abdominal muscles, only with marginally longer operation time, without compromising graft and recipient survival. Kok et al. described the differences between MIDN and ODN. The median operation time was 158 and $144 \mathrm{~min}(\mathrm{p}=0.02)$. Blood loss was significantly less after MIDN (median 210 vs. 300 $\mathrm{ml}, \mathrm{p}=0.01)$. Intra-operatively, $4(7 \%)$ and $1(1 \%)$ bleeding episodes occurred. Postoperatively, complications occurred in $12 \%$ in both groups. Hospital stay was 4 and 6 days $(p<0.001)$. In one $(2 \%)$ and $11(13 \%)$ donors $(p=0.02)$ late complications related to the incision occurred. Neipp at al. found an operating time of $129 \mathrm{~min}$ for ODN and $133 \mathrm{~min}$ for 
MIDN. Blood loss and morphine requirements were not reported. Early complications occurred in $7 \%$ following ODN and in $4 \%$ following MIDN. Late complications were observed in $21 \%$ after ODN and $1 \%$ after MIDN. The mean hospital stay was significantly longer following ODN (7.5 vs. 6.4 days). [38, 39]

There is evidence to prefer mini-incision techniques to classic flank incisions (level III). Notwithstanding MIDN was a step forward, there were still disincentives to the open, not minimally invasive approach; this may be a drawback for possible live kidney donors.

\subsubsection{Hand-assisted techniques}

The hand-assisted laparoscopic (HALDN) and retroperitoneoscopic (HARP) donor nephrectomy start with an incision for the handport. With the HARP technique the retroperitoneal space is created manually (or with a balloon or catheter) through the pfannenstiel incision. An endoscope is introduced and one or two other ports are inserted. The retroperitoneum is insufflated to $12-\mathrm{cm} \mathrm{H}_{2} \mathrm{O}$ carbon dioxide pressure. In the HALDN after establishing a pneumoperitoneum, the colon is mobilized and displaced medially. Further dissection and preparation of the vascular structures is performed as described above. The renal artery and vein are divided using an endoscopic stapler and the kidney is removed manually.

Hand-assisted donor nephrectomy can be performed transperitoneally (HALDN) and retroperitoneally (HARP). Hand-assistance can be performed during the whole operation or only during the stapling- and extraction phase, with different incisions for hand introduction. Periumbilical incision, a midline supraumbilical incision, a midline infraumbilical incision, or a Pfannenstiel incision have been described in several studies.

The advantages of hand-assisted donor nephrectomy above conventional laparoscopy include the ability to use tactile feedback, easier and rapid control of bleeding by digital pressure, better exposure and dissection of structures, rapid kidney removal. Overall, these advantages may lead to a shorter skin to skin- and warm ischemia time. With the retroperitoneal approach there is less chance to injure the intra-abdominal organs. This is an important advantage in times where safety of laparoscopic technique is still questioned.

Hand-assisted transperitoneal has been compared to laparoscopic donor nephrectomy. Most studies describing hand-assisted laparoscopic (transperitoneally) donor nephrectomy conclude that the hand-assisted technique is superior to the laparoscopic technique regarding operative time. Blood loss was less, WIT, and hospital stay were shorter for the HALDN. Complications and morphine requirement, convalescence time, and graft and recipient survival were similar in most studies. One randomized controlled trial of Bargmann et al. shows no difference between the two techniques, and an even longer operative time for the hand-assisted laparoscopic technique.[40]

Data on hand-assisted retroperitoneal compared to laparoscopic donor nephrectomy are scarce. Only three studies compare left-sided hand-assisted retroperitoneoscopic with laparoscopic donor nephrectomy. Two centers posed the hand-assisted retroperitoneoscopic approach as an alternative for right-sided donor nephrectomy. Sundqvist et al. performed a prospective study, comparing HARP $(n=11), \operatorname{LDN}(n=14)$ and open donor nephrectomy $(n=$ 11). Hand-assisted retroperitoneoscopic donor nephrectomy had a significantly shorter operation time compared to LDN (145 min vs 218 minutes, $\mathrm{p}<0.05)$. Gjertsen et al. performed a retrospective study, comparing HARP $(n=11), \operatorname{LDN}(n=15)$ and open donor nephrectomy $(n=$ 25). Reduced operation time was observed for the HARP group compared with the LDN (166 
min vs $244 \mathrm{~min})$. Wadstrom et al. reported operative time for the HARP $(n=18)$ was significantly shorter than that of the LDN ( $\mathrm{n}=11)$ (270 vs $141 \mathrm{~min}$ ). Warm ischemia time was significantly longer in the LDN ( $297 \mathrm{vs} 177 \mathrm{sec})$. There was no statistically significant difference in operative bleeding or length of hospital stay between the groups. [41-43]

Outcome of most studies comparing different minimal invasive techniques are similar in terms of intra- and post-operative outcome for donor and recipient, and seems promising, but studies are small, too heterogeneous, and with low level of evidence. There is one randomized controlled trial described in literature and done, but not yet published.
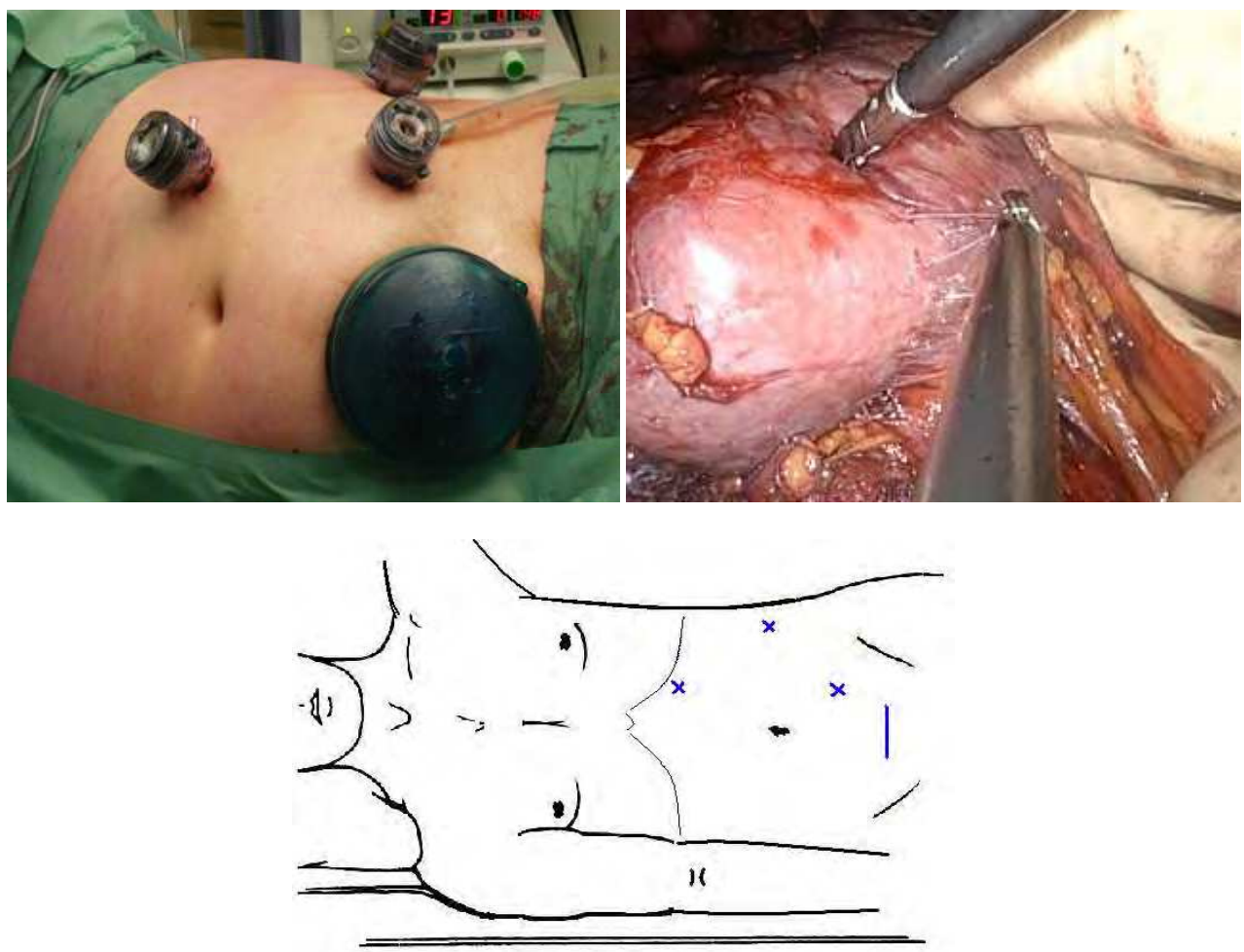

Fig. 4. Hand-assisted retroperitoneal donor nephrectomy and placement of the incisions.

\subsubsection{LDN vs ODN}

Laparoscopic donor nephrectomy is performed with the donor in lateral decubitus position. In short, a 10-mm trocar is introduced under direct vision. The abdomen is insufflated to 12$\mathrm{cm} \mathrm{H}_{2} \mathrm{O}$ carbon dioxide pressure. A $30^{\circ}$ video endoscope and 3 to 4 additional trocars are introduced. The colon is mobilized and displaced medially. Opening of the renal capsule and division of the perirenal fat is facilitated using an ultrasonic device or diathermia. After identification and careful dissection of the ureter, the renal artery, and the renal vein, a pfannenstiel incision is made. An endobag is introduced into the abdomen. The ureter is clipped distally and divided. The renal artery and vein are divided using an endoscopic stapler. The kidney is placed in the endobag and extracted through the pfannenstiel incision. 
Since MIDN was introduced, evidence has mounted that the laparoscopic approach may be superior to conventional open donor nephrectomy.

Various non-randomized studies have led to the similar conclusion, despite longer operation times and longer warm ischemia time LDN results in shorter hospital stay, faster recovery, less pain, less blood loss, earlier return to work, and better quality of life as compared to the conventional open approach. Most of these studies presented (handassisted) laparoscopic donor nephrectomy as an alternative rather than as the preferred technique. Several case series from large volume centres in the United States tried to prove the feasibility and safety of the laparoscopic technique. Leventhal et al. reported a group of 500 patients with an overall rate of intra- and postoperative complications of respectively $2.8 \%$ and $3.4 \%$. There were 9 conversions $(1.8 \%)$, of which 6 were in the first 100 cases. Thirty patients experienced an intraoperative or procedure-related complication (6.0\%).[44]

The remaining issues surrounding the use of laparoscopic donor nephrectomy, including long-term follow-up, complications, and donor and recipient safety, are gradually being solved. Nowadays it is the standard technique in a lot of centres for surgeons experienced in laparoscopic techniques. There is level I evidence for the superiority of LDN, but safety remains an issue, and must be adequately studied.

\subsubsection{LDN vs MIDN}

One RCT, one retrospective study, and one meta-analysis (Level I evidence) aimed to assess the superiority of either the laparoscopic or the minimally invasive open approach (MIDN).

The RCT concluded that laparoscopic donor nephrectomy results in a better quality of life compared with MIDN with equal safety and graft function. Compared to mini incision open donor nephrectomy $(n=50)$, laparoscopic donor nephrectomy $(n=50)$ resulted in longer skinto-skin time (median $221 \mathrm{v} 164$ minutes, $\mathrm{p}<0.001)$, longer warm-ischemia time $(6 \mathrm{v} 3$ minutes, $\mathrm{p}<0.001)$, less blood loss $(100 \mathrm{v} 240 \mathrm{ml}, \mathrm{p}<0.001)$, and not a statistically different complication rate (intraoperatively $12 \% \mathrm{v} 6 \%, \mathrm{P}=0.49$, postoperatively both $6 \%$ ). After laparoscopic nephrectomy, donors required less morphine $(16 \mathrm{v} 25 \mathrm{mg}, \mathrm{P}=0.005)$ and shorter hospital stay ( $3 \mathrm{v} 4$ days, $\mathrm{P}=0.003$ ).[9] Lewis et al. performed a prospective study comparing traditional open, minimal-incision, and laparoscopic donor nephrectomy. They found median operating and first warm ischemia times that were longer for LDN than for MIDN (232vs147 min, P < 0.001; 2, 4 min, $\mathrm{P}<0.01)$. Blood loss was not significantly higher for LDN (340 vs $260 \mathrm{ml}$ ). Hospital stay was significantly shorter for LDN (4.4 and 6 days), and postoperative morphine requirements were similar (71 vs $86, \mathrm{P}<0.0001$ ), but the duration of the PCA was shorter $(41,53$ hours, $\mathrm{p}<0.05)$. Donors returned to work quicker after LDN than after MIDN (6vs 11vs 10; $\mathrm{P}=0.055)$. [45]

The laparoscopic live donor nephrectomy is technically more demanding than the open approach, with a prolonged learning curve. Remarkably, the learning curve of the open approach was never described. Due to the learning curve, introduction of the laparoscopic method in small centers can be difficult and maybe other techniques are being preferred for safety reasons.

\subsubsection{Transperitoneal versus retroperitoneal endoscopic donor nephrectomy}

Transperitoneal and retroperitoneal donor nephrectomy can be practiced with or without hand-assistance. Endoscopic and hand-assisted trans- and retroperitoneal donornephrectomy are described above. Whether to take the retroperitoneal or the transperitoneal route for donor nephrectomy has not been solved yet. The limited retroperitoneal space makes it technically more challenging but provides superior access to 
posterior and particularly posteromedial space. Operative time is shorter in the transperitoneal group, and WIT tends to be longer. There is limited data confirming both techniques have equal complications, hospital stay, and graft and recipient survival.

\subsubsection{Robotic-assisted donor nephrectomy}

Robotic-assisted donor nephrectomy with the da Vinci robot can be performed with or without hand-assistance. The patient is placed in lateral decubitus position. Four trocars are used; two for the surgeon, a camera port and a port for the assistant. The surgeon is seated in a distant console. The images can be magnified and the movement of the articulated arm of the robot reproduces the action of the human wrist. An additional hand-assistance port in the midline can also be used. The nephrectomy is carried out in the same way as the laparoscopic procedure.

There are few articles on robot-assisted donor nephrectomy, but perhaps this will be expanded in this evolving field. Theoretical advantages of the robot-assisted technique are the combination of robotics and computer imaging, to enable microsurgery in a laparoscopic environment. There is one study comparing the robot-assisted donor nephrectomy $(n=13)$ to the open donor nephrectomy $(n=13)$. Renoult et al. found a longer operative- and warm ischemia time in the robot-assisted group (186 vs $113 \mathrm{~min}, \mathrm{p}<0.001$ ). There was no conversion in the robot-assisted group. There was one complication in both groups, a deep venous thrombosis in the robot-assisted group, and an acute pyelonephritis in the open group. Hospital stay was shorter after the RALD procedure $(5.84+/-1.8$ vs $9.69+/-2.2$ days, $\mathrm{p}<0.001)$. Kidney function was equivalent for all donors, at 5 days and 1 month after nephrectomy. All kidneys started functioning immediately after the transplantation.[46]

\begin{tabular}{|l|c|l|}
\hline & $\begin{array}{l}\text { Level of } \\
\text { evidence }\end{array}$ & Type of evidence \\
\hline $\begin{array}{l}\text { Conventional open VS mini- } \\
\text { incision donor nephrectomy }\end{array}$ & III & $\begin{array}{l}\text { - Prospective study } \\
-\begin{array}{l}\text { Retrospective studies, historical } \\
\text { controls }\end{array}\end{array}$ \\
\hline $\begin{array}{l}\text { Mini-incision VS laparoscopic } \\
\text { donornephrectomy }\end{array}$ & I & $\begin{array}{l}\text { - RCT } \\
- \text { Prospective study } \\
- \text { Meta-analysis }\end{array}$ \\
\hline $\begin{array}{l}\text { Laparoscopic VS hand-assisted } \\
\text { laparoscopic donornephrectomy }\end{array}$ & II & $\begin{array}{l}- \text { RCT } \\
- \text { Prospective studies } \\
- \text { Retrospective studies, historical } \\
\text { controls }\end{array}$ \\
\hline $\begin{array}{l}\text { Laparoscopic VS hand-assisted } \\
\text { retroperitoneal } \\
\text { donornephrectomy }\end{array}$ & III & $\begin{array}{l}\text { - Prospective } \\
- \text { Retrospective }\end{array}$ \\
\hline $\begin{array}{l}\text { Robot-assisted VS open donor } \\
\text { nephrectomy }\end{array}$ & III & - Retrospective, historical controls \\
\hline
\end{tabular}

Dols et al, Transpl Int. 2010 Feb;23(2):121-30.

Table 4. Operative techniques for live kidney donation; level and type of evidence. 


\subsection{Intra-operative complications}

Intra-operative complications are important to note because of the high impact on donor and recipient life. There are not many studies describing the intra-operative complications as they are difficult to score uniformly. Only studies where a research fellow is present at the operation theater can give some information about the intra-operative complication rate. The rate of intra-operative complications is described in literature for the different techniques from 2 to $28 \%$ (table 5). There are no randomized studies reporting the intraoperative complications, as the inclusion number will be far too high.

Intra-operative complications are scored differently in all studies. Sorts of complications are: excessive blood loss, lesions to the small and large bowel, bladder, ureter and the kidney itself. We advocate a uniform system to score the complications by grade. The table below shows the modified Clavien scoring system, as we use for our intra- and postoperative complications (table 6).[47]

\section{Post-operative}

\subsection{Outcome}

Live kidney donation is relatively safe, but keeping in mind the otherwise healthy donor, it is never safe enough. Previous studies have shown that morbidity and mortality rates after LDN are low, with mortality estimated at $0.03 \%$. Safety is gaining increasingly more interest and remains the big conundrum in minimal-invasive surgery. Safety consists of a few issues, not only the real complications but also the near complications or small intra and postoperative complications.

\subsubsection{Long-term follow up}

Adequate follow-up may identify donors who develop complications and to monitor the risks of life kidney donation. Donors who develop hypertension or a diminished kidney function may be identified and it may also aid donors from a social point of view. Some donors who struggle with their recovery or experience problems resuming work can be helped.

Literature indicates that the life expectancy of living kidney donors is similar to that of persons who have not donated a kidney. The risk of developing end-stage renal disease does not appear to be increased among kidney donors, and their current health seems to be similar to that of the general population. A lot of studies report on quality of life, and their quality of life appears to be very good. These outcomes may be a direct consequence of the meticulous routine screening of donors for important health conditions related to kidney disease at the time of donation.

After live kidney donation a reduction in total GFR of around 30\% is described. This change in the GFR did not appear to increase over time. Kidney donation, or nephrectomy, is followed by a compensatory increase in the GFR in the remaining kidney to about $70 \%$ of pre nephrectomy values. The direct relationship between time since donation and the GFR may reflect not only a young age at donation but also the afore mentioned meticulous screening for underlying kidney disease that live kidney donors undergo. Compensatory hemodynamic changes in some animal models after a reduction of $50 \%$ or more in renal mass have been reported to be ultimately deleterious. There has been a concern that kidney donors might have damage in addition to the normal loss of kidney function with age. 


\begin{tabular}{|c|c|c|}
\hline & Intraoperative (\%) & Postoperative (\%) \\
\hline Flank incision & $2-13$ & $8-35$ \\
\hline MIDN & $4-7$ & $1-15$ \\
\hline LDN & $2.8-25$ & $0-43$ \\
\hline HALDN/HARP & $4-28$ & $0-15$ \\
\hline
\end{tabular}

Dols et al, Transpl Int. 2010 Feb;23(2):121-30.

Table 5. Intraoperative and postoperative complications (\%) of the different types of operation techniques for live donor nephrectomy.

\begin{tabular}{|c|c|c|c|c|c|}
\hline LDN & Grade* & $\begin{array}{c}\text { Percentage of all } \\
\text { complications }(n=10)\end{array}$ & $\begin{array}{l}\text { Percentage of total } \\
\text { series }(n=40)\end{array}$ & Complications & $\begin{array}{l}\text { Patients } \\
\text { (n) }\end{array}$ \\
\hline & 1 & $50(n=5)$ & 12.5 & Blood loss $<500 \mathrm{ml}$ & 5 \\
\hline & 2 & $50(n=5)$ & 3.8 & & 5 \\
\hline & $2 a$ & $10(n=1)$ & 2.5 & Blood loss $>500 \mathrm{ml}$ & 1 \\
\hline & $2 b$ & $30(n=3)$ & 7.5 & Small bowel injury & 1 \\
\hline & & & & Bladder lesion & 1 \\
\hline & & & & Ureteral injury & 1 \\
\hline & $2 c$ & $10(n=1)$ & 2.5 & $\begin{array}{l}\text { No overview, } \\
\text { conversion to hand- } \\
\text { assisted LDN }\end{array}$ & 1 \\
\hline & 3 & 0 & 0 & 0 & 0 \\
\hline & 4 & 0 & 0 & 0 & 0 \\
\hline HARP & Grade* & $\begin{array}{c}\text { Percentage of all } \\
\text { complications }(n=2)\end{array}$ & $\begin{array}{l}\text { Percentage of total } \\
\text { series }(n=20)\end{array}$ & Complications & $\begin{array}{l}\text { Patients } \\
\text { (n) }\end{array}$ \\
\hline & 1 & 0 & 0 & 0 & 0 \\
\hline & 2 & $100(n=2)$ & 10 & 0 & 2 \\
\hline & $2 a$ & $50(\mathrm{n}=1)$ & 5 & Lumbar vein injury & 1 \\
\hline & $2 b$ & 0 & 0 & 0 & 0 \\
\hline & $2 c$ & $50(\mathrm{n}=1)$ & 5 & $\begin{array}{c}\text { Lumbar vein injury, } \\
\text { conversion }\end{array}$ & 1 \\
\hline & 3 & 0 & 0 & 0 & 0 \\
\hline & 4 & 0 & 0 & 0 & 0 \\
\hline
\end{tabular}

* 1 Non-life-threatening complications

2a Complications requiring only use of drug therapy, blood loss $>500 \mathrm{~mL}$ or $\mathrm{Hb}$ drop $>2 \mathrm{~g} / \mathrm{dL}$ and/or resulting in hemodynamic instability or $\mathrm{Hb}<8 \mathrm{~g} / \mathrm{dL}$, readmission to hospital for medical management or prolongation of hospital stay for more than three times median length of stay. $2 \mathrm{~b}$ Complications requiring additional therapeutic intervention (ie operation for bowel obstruction, interventional radiologic procedure) or readmission to the hospital for intervention. 2c Complications requiring open conversion of LDN for patient management

3 Any complication with residual or lasting functional disability

4 Leads to renal failure or death in the donor

Dols et al, Transpl Int. 2010 Apr 1;23(4):358-63.

Table 6. Intraoperative complications of HARP and LDN with grading by severity. 
Information regarding the long-term renal consequences of reduced renal mass in humans has come mainly from studies of children born with a reduced number of functioning nephrons, reports of focal sclerosis in patients with unilateral renal agenesis, and studies of World War II veterans who lost a kidney as a result of trauma. There are also numerous studies that have examined renal function in kidney donors. Although isolated cases of renal failure have been reported, no large study has shown evidence of progressive deterioration of renal function. Data suggests that there is no excess risk of ESRD in donors and confirms the view that factors linked to a reduced GFR in donors are the same as those that have been observed in the general population - namely, age and overweight. [3]

In previous studies the prevalence of hypertension and albuminuria in kidney donors were similar to those in controls who were matched for age, sex, race or ethnic group, and bodymass index, even two decades after donation.

\section{Conclusion}

Kidney transplantation is the therapy of choice for patients with end-stage renal disease and gives the best chance on long-term survival and a good quality of life. In the recent years there have been many changes in the living kidney donation programmes. Higher numbers of donors were operated due to less invasive surgical techniques, acceptable long-term safety and good transplant outcome. The surgical practice has evolved from the open lumbotomy, through mini-incision open donor nephrectomy (MIDN), to minimally invasive laparoscopic techniques. All different minimal invasive techniques, like standard laparoscopic, hand-assisted laparoscopic, hand-assisted retroperitoneoscopic and pure retroperitoneoscopic live donor nephrectomy, are practiced these days. Different centres have different visions on which technique to use, all depending on the expertise with each technique. In the literature there is Level I evidence that minimally invasive techniques are preferred above open, and mini-incision donor nephrectomy.

As LDN with or without hand-assistance has become the gold standard, the role for handassisted retroperitoneal and pure retroperitoneal donor nephrectomy requests further clarification. Outcome of most small, not randomized, studies comparing different minimal invasive techniques are similar in terms of intra- and post-operative outcome for donor and recipient.

Many centres in Europe implemented the LDN, but there are still a lot of centres where open donor nephrectomy is performed. For those centres that did not adopt the LDN, modified open or hand-assisted techniques may become a feasible alternative.

Safety of the laparoscopic technique is still debated, and the difficulty is that safety has never been studied as a primary endpoint because the sample size would be enormous. Therefore complications and conversions need to be registered in a national or international database.

The donor must be left with the best kidney and left as well as right may be selected for donation nowadays. Furthermore, donors having kidneys with multiple vessels and obese donors can be included if well-selected and offered proper follow-up. Future directions will have to focus on safety of surgical techniques, and long-term follow-up of live kidney donors and their recipients to guarantee a high standard of quality for the living related kidney donation programs.

\section{References}

[1] Kuss, R., J. Teinturier, and P. Milliez, [Some attempts at kidney transplantation in man.]. Mem Acad Chir (Paris), 1951. 77(22-23-24): p. 755-64. 
[2] Friedman, A.L., et al., Fatal and Nonfatal Hemorrhagic Complications of Living Kidney Donation. Ann Surg, 2006. 243(1): p. 126-130.

[3] Ibrahim, H.N., et al., Long-term consequences of kidney donation. N Engl J Med, 2009. 360(5): p. 459-69.

[4] Kok, N.F., et al., Psychosocial and physical impairment after mini-incision open and laparoscopic donor nephrectomy: A prospective study. Transplantation, 2006. 82(10): p. 1291-7.

[5] Kok, N.F., et al., The current practice of live donor nephrectomy in europe. Transplantation, 2006. 82(7): p. 892-7.

[6] Laupacis, A., et al., A study of the quality of life and cost-utility of renal transplantation. Kidney Int, 1996. 50(1): p. 235-42.

[7] Matas, A.J., et al., 2,500 living donor kidney transplants: a single-center experience. Ann Surg, 2001. 234(2): p. 149-64.

[8] Liem, Y.S., et al., Living renal donors: optimizing the imaging strategy--decision- and costeffectiveness analysis. Radiology, 2003. 226(1): p. 53-62.

[9] Kok, N.F., et al., Comparison of laparoscopic and mini incision open donor nephrectomy: single blind, randomised controlled clinical trial. BMJ, 2006. 333(7561): p. 221.

[10] Delmonico, F.L., A Report of the Amsterdam Forum On the Care of the Live Kidney Donor: Data and Medical Guidelines. Transplantation, 2005. 79(6 Suppl): p. S53-66.

[11] Gluecker, T.M., et al., Comparison of CT angiography with MR angiography in the preoperative assessment of living kidney donors. Transplantation, 2008. 86(9): p. 1249-56.

[12] Kok, N.F., et al., Complex vascular anatomy in live kidney donation: imaging and consequences for clinical outcome. Transplantation, 2008. 85(12): p. 1760-5.

[13] Mandal, A.K., et al., Should the indications for laparascopic live donor nephrectomy of the right kidney be the same as for the open procedure? Anomalous left renal vasculature is not a contraindiction to laparoscopic left donor nephrectomy. Transplantation, 2001. 71(5): p. 660-4.

[14] Abrahams, H.M., et al., Technique, indications and outcomes of pure laparoscopic right donor nephrectomy. J Urol, 2004. 171(5): p. 1793-6.

[15] Husted, T.L., et al., Laparoscopic right living donor nephrectomy. Transplant Proc, 2005. 37(2): p. 631-2.

[16] Kay, M.D., et al., Comparison of right and left laparoscopic live donor nephrectomy. BJU Int, 2006. 98(4): p. 843-4.

[17] Lind, M.Y., et al., Right-sided laparoscopic live-donor nephrectomy: is reluctance still justified? Transplantation, 2002. 74(7): p. 1045-8.

[18]Maciel, R.F., Hand-Assisted LaparoscopicLiveDonorNephrectomy(Right-Sided Approach): Experience Obtained From 31 Cases. Transplantation Proceedings, 2007. 39(8): p. 2476.

[19] Minnee, R.C., et al., Left or right kidney in hand-assisted donor nephrectomy? A randomized controlled trial. Transplantation, 2008. 85(2): p. 203-8.

[20] Narita, S., et al., Outcome of right hand-assisted retroperitoneoscopic living donor nephrectomy. Urology, 2006. 67(3): p. 496-500; discussion 500-1.

[21] Saad, S., et al., Laparoscopic live donor nephrectomy for right kidneys: Experience in a German community hospital. Surg Endosc, 2008. 22(3): p. 674-8.

[22] Desai, M.R., et al., Outcome of renal transplantation with multiple versus single renal arteries after laparoscopic live donor nephrectomy: a comparative study. Urology, 2007. 69(5): p. 824-7.

[23] Oh, H.K., A. Hawasli, and G. Cousins, Management of renal allografts with multiple renal arteries resulting from laparoscopic living donor nephrectomy. Clin Transplant, 2003. 17(4): p. 353-7.

[24] Saidi, R., et al., Living donor kidney transplantation with multiple arteries: recent increase in modern era of laparoscopic donor nephrectomy. Arch Surg, 2009. 144(5): p. 472-5. 
[25] De La Vega, L.S., et al., Patient and graft outcomes from older living kidney donors are similar to those from younger donors despite lower GFR. Kidney Int, 2004. 66(4): p. 1654-61.

[26] Iordanous, Y., et al., Recipient outcomes for expanded criteria living kidney donors: the disconnect between current evidence and practice. Am J Transplant, 2009. 9(7): p. 1558-73.

[27] Johnson, S.R., et al., Older living donors provide excellent quality kidneys: a single center experience (older living donors). Clin Transplant, 2005. 19(5): p. 600-6.

[28] Kerr, S.R., et al., Living donors >55 years: to use or not to use? Transplantation, 1999. 67(7): p. 999-1004.

[29] Minnee, R.C., et al., Older living kidney donors: surgical outcome and quality of life. Transplantation, 2008. 86(2): p. 251-6.

[30] Naumovic, R., et al., Effect of donor age on the outcome of living-related kidney transplantation. Transpl Int, 2005. 18(11): p. 1266-74.

[31] Dols, L.F., et al., Living kidney donors: impact of age on long-term safety. Am J Transplant. 11(4): p. 737-42.

[32] Davis, C.L. and F.L. Delmonico, Living-Donor Kidney Transplantation: A Review of the Current Practices for the Live Donor. J Am Soc Nephrol, 2005. 16(7): p. 2098-2110.

[33] Heimbach, J.K., et al., Obesity in living kidney donors: clinical characteristics and outcomes in the era of laparoscopic donor nephrectomy. Am J Transplant, 2005. 5(5): p. 1057-64.

[34] Kok, N.F., et al., Laparoscopic donor nephrectomy in obese donors: easier to implement in overweight women? Transpl Int, 2007. 20(11): p. 956-61.

[35] Lynch, R.J., et al., Obesity, surgical site infection, and outcome following renal transplantation. Ann Surg, 2009. 250(6): p. 1014-20.

[36] Massarweh, N.N., et al., High body mass index and short- and long-term renal allograft survival in adults. Transplantation, 2005. 80(10): p. 1430-4.

[37] Srivastava, A., et al., Subcostal versus transcostal mini donor nephrectomy: is rib resection responsible for pain related donor morbidity. J Urol, 2003. 170(3): p. 738-40.

[38] Kok, N.F., et al., Mini-incision open donor nephrectomy as an alternative to classic lumbotomy: evolution of the open approach. Transpl Int, 2006. 19(6): p. 500-5.

[39] Neipp, M., et al., Living donor nephrectomy: flank incision versus anterior vertical miniincision. Transplantation, 2004. 78(9): p. 1356-61.

[40] Bargman, V., et al., Randomized trial of laparoscopic donor nephrectomy with and without hand assistance. J Endourol, 2006. 20(10): p. 717-22.

[41] Gjertsen, H., et al., Introduction of hand-assisted retroperitoneoscopic living donor nephrectomy at Karolinska University Hospital Huddinge. Transplant Proc, 2006. 38(8): p. $2644-5$.

[42] Sundqvist, P., et al., Hand-assisted retroperitoneoscopic live donor nephrectomy in comparison to open and laparoscopic procedures: a prospective study on donor morbidity and kidney function. Transplantation, 2004. 78(1): p. 147-53.

[43] Wadstrom, J., P. Lindstrom, and B.M. Engstrom, Hand-assisted retroperitoneoscopic living donor nephrectomy superior to laparoscopic nephrectomy. Transplant Proc, 2003. 35(2): p. 782-3.

[44] Leventhal, J.R., et al., Laparoscopic donor nephrectomy 1997 to 2003: lessons learned with 500 cases at a single institution. Surgery, 2004. 136(4): p. 881-90.

[45] Lewis, G.R., et al., A comparison of traditional open, minimal-incision donor nephrectomy and laparoscopic donor nephrectomy. Transpl Int, 2004. 17(10): p. 589-95.

[46] Renoult, E., et al., Robot-assisted laparoscopic and open live-donor nephrectomy: a comparison of donor morbidity and early renal allograft outcomes. Nephrol Dial Transplant, 2006. 21(2): p. 472-7.

[47] Kocak, B., et al., Proposed classification of complications after live donor nephrectomy. Urology, 2006. 67(5): p. 927-31. 


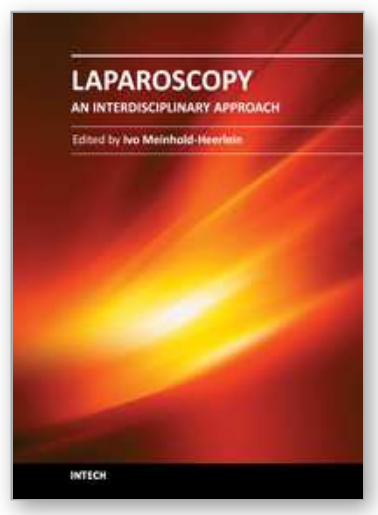

\section{Laparoscopy - An Interdisciplinary Approach}

Edited by Dr. Ivo Meinhold-Heerlein

ISBN 978-953-307-299-9

Hard cover, 146 pages

Publisher InTech

Published online 12, September, 2011

Published in print edition September, 2011

Over the last decades an enormous amount of technical advances was achieved in the field of laparoscopy. Many surgeons with surgical, urological, or gynaecological background have contributed to the improvement of this surgical approach which today has an important and fixed place in the daily routine. It is therefore comprehensible to compose a book entitled laparoscopy serving as a reference book for all three disciplines. Experts of each field have written informative chapters which give practical information about certain procedures, indication of surgery, complications and postoperative outcome. Wherever necessary, the appropriate chapter is illustrated by drawings or photographs. This book is advisable for both beginner and advanced surgeon and should find its place in the libraries of all specialties â€" surgery, urology, and gynecology.

\section{How to reference}

In order to correctly reference this scholarly work, feel free to copy and paste the following:

Leonienke F.C. Dols and Jan N.M. ljzermans (2011). Laparoscopic Living Kidney Donation, Laparoscopy - An Interdisciplinary Approach, Dr. Ivo Meinhold-Heerlein (Ed.), ISBN: 978-953-307-299-9, InTech, Available from: http://www.intechopen.com/books/laparoscopy-an-interdisciplinary-approach/laparoscopic-living-kidneydonation

\section{INTECH}

open science | open minds

\author{
InTech Europe \\ University Campus STeP Ri \\ Slavka Krautzeka 83/A \\ 51000 Rijeka, Croatia \\ Phone: +385 (51) 770447 \\ Fax: +385 (51) 686166 \\ www.intechopen.com
}

\author{
InTech China \\ Unit 405, Office Block, Hotel Equatorial Shanghai \\ No.65, Yan An Road (West), Shanghai, 200040, China \\ 中国上海市延安西路65号上海国际贵都大饭店办公楼 405 单元 \\ Phone: +86-21-62489820 \\ Fax: +86-21-62489821
}


(C) 2011 The Author(s). Licensee IntechOpen. This chapter is distributed under the terms of the Creative Commons Attribution-NonCommercialShareAlike-3.0 License, which permits use, distribution and reproduction for non-commercial purposes, provided the original is properly cited and derivative works building on this content are distributed under the same license. 